TITLE:

\title{
Cardiovascular surgery for realization of regenerative medicine.
}

\author{
$\operatorname{AUTHOR}(\mathrm{S})$ :
}

Masumoto, Hidetoshi; Sakata, Ryuzo

\section{CITATION:}

Masumoto, Hidetoshi ...[et al]. Cardiovascular surgery for realization of regenerative medicine.. General thoracic and cardiovascular surgery 2012, 60 (11): 744-755

ISSUE DATE:

2012-11

URL:

http://hdl.handle.net/2433/164074

\section{RIGHT:}

The final publication is available at www.springerlink.com; この論文は 出版社版でありません。引用の際には出版社版をご確認ご利用くださ $\omega_{\circ}$; This is not the published version. Please cite only the published version. 


\title{
Title:
}

\section{Cardiovascular surgery for realization of regenerative medicine}

\author{
Hidetoshi Masumoto, $\mathrm{MD}^{1,2}$, Ryuzo Sakata, $\mathrm{MD}^{1 *}$ \\ ${ }^{1}$ Department of Cardiovascular Surgery, Kyoto University Graduate School of Medicine,
} Kyoto, Japan

${ }^{2}$ Department of Cell Growth and Differentiation, Center for iPS Cell Research and Application (CiRA), Kyoto University, Kyoto, Japan

*Correspondence information for corresponding author:

Ryuzo Sakata, MD

Department of Cardiovascular Surgery, Kyoto University Graduate School of Medicine

54 Shogoin Kawahara-cho, Sakyo-ku, Kyoto 606-8507, Japan

TEL: +81-75-751-3784, FAX: +81-75-751-4960

E-mail: sakatar@kuhp.kyoto-u.ac.jp

Key words: cardiovascular surgery, regenerative medicine, stem cell therapy 


\section{Abstract}

Regenerative medicine is emerging as a new approach to the treatment of severe cardiovascular diseases that are resistant to conventional therapies. While the type of cell transplanted (e.g., pluripotent stem cells, bone marrow-derived stem cells, skeletal myoblasts, or cardiac stem cells) influences the outcome of stem cell transplantation, the method of transplantation is also important, as the efficiency of engraftment after simple needle injection is poor. Scaffold-free cell sheet transplantation technology is one of the most promising methods in this regard. Although the results of clinical trials of stem cell therapy have been marginal to date, further elucidation of the actual mechanisms of cardiac repair following cell therapy would enhance the potential for full-scale implementation of stem cell therapy. In addition to stem cell therapy, the field of cardiovascular regenerative medicine includes interspecific chimera technology, drug delivery systems using biodegradable materials, and gene therapy. Integration of these new modalities with conventional therapies will be important to realizing the goal of cardiovascular regenerative medicine tailored to the condition of each individual patient. Cardiovascular surgery would be an excellent means of carrying out this strategy and could potentially resolve the health problems of the increasing 
1

2

number of advanced cardiovascular patients. Herein, we review the recent basic and clinical research associated with the realization of regenerative medicine in the field of cardiovascular surgery. (220 words) 


\section{Introduction}

Cardiovascular disease remains the leading cause of death worldwide. In Japan, over 57,000 cardiovascular surgeries for treatment of advanced cardiovascular diseases are performed annually ${ }^{1}$. However, the surgical treatment of severe heart failure is limited by the shortage of donors for heart transplantation and by the risk for serious complications, such as infection or cerebral thrombosis, after the implantation of ventricular assist devices. This health problem has prompted research into new therapeutic approaches, including cardiac regeneration ${ }^{2}$. Numerous valuable outcomes over more than a decade of basic research are now on the horizon of translation to clinical application ("from bench to clinic"), and the expectations from society are considerable. The field of cardiovascular surgical research, as the practical setting of such translational research, is now gathering significant attention from basic researchers. The results of basic research must be proven by preclinical experiments in animal disease models that mimic human diseases before the techniques can be applied clinically, and cardiovascular surgeons, as experts in human surgical treatments, are therefore the personnel best-suited to make practical contributions to advancing regenerative medicine research. 
In this review, we introduce recent basic and clinical research related to the field of cardiovascular surgery, including the different therapeutic approaches to, drawbacks of, and future expectations for new regenerative therapies for cardiovascular diseases.

\section{Cell transplantation}

Acute ischemic injury and chronic cardiomyopathies lead to permanent loss of cardiac tissue and, consequently, heart failure. Cell transplantation is thought to be an ideal therapeutic method for replacing lost myocardium ${ }^{3,4}$. Of the available cell sources, stem cells are now widely preferred for research or clinical trials concerning cardiac cell therapy $y^{2,5}$. The discovery of various stem cell populations possessing cardiogenic potential and the subsequent development of methods to isolate and expand these cells have begun to shape the notion of restorative therapy. In spite of the great deal of knowledge gained through numerous basic research studies, significant barriers to true cardiac regeneration remain, and the field still lacks results sufficiently conclusive to support full-scale implementation of such therapies. Very few of the transplanted tissue stem cells seem to differentiate into mature cardiovascular cell types, suggesting that transplanted cells exert paracrine effects by which humoral factors induce or support 
favorable processes, including angiogenesis, prevention of apoptosis, and promotion of healing, in the injured myocardium rather than differentiating into renewed myocardium ${ }^{2}$. In this section, we introduce the present research achievements in stem cell therapy using various cell types, including clinical trials employing said cell sources, as well as the transplantation technologies that best support effective engraftment of the transplants. The characteristics of each stem cell population with respect to therapeutic potential are summarized in Table 1.

\section{Pluripotent stem cells}

Embryonic stem cells (ESCs) can be removed from the inner cell mass of the blastocyst and expanded in vitro practically indefinitely ${ }^{6}$. In culture, ESCs remain undifferentiated and pluripotent. When allowed to differentiate, ESCs can give rise to most somatic cell lineages ${ }^{7}$; their regenerative capacity is thus theoretically limitless. The advantages of these properties of ESC are especially significant for the heart as opposed to other organs, such as endocrine or sensory organs, as the heart functions as an assembly of many types of cells, including cardiomyocytes and others, and as numerous $\left(>10^{8}\right)$ heart-composing cells might be required to fully repair a damaged human heart. The differentiation of ESCs can be driven towards cardiomyocytes or 
other vascular cell types by culture as monolayers or embryoid bodies in various growth media $^{8-11}$. These cells can then be transplanted into the heart. This approach to repairing cardiac tissue has been tested in preclinical studies with encouraging results ${ }^{10,12}$. In fact, of the various stem cell populations studied so far, ESCs have demonstrated perhaps the greatest capacity for cardiac cell differentiation and long-term cell survival ${ }^{13}$.

To date, no human trials of the use of ESCs for cardiac repair have been attempted. There have been 3 main concerns regarding the use of ESC transplantation as a treatment modality. First, the differentiating cell mass contains cells from 3 germ layers, the ectoderm, mesoderm, and endoderm, and therefore possesses the capacity to differentiate along any or all of these lineages. This potential increases the risk of teratoma formation at the transplantation site. Although such teratomas are believed to be largely benign in vivo, some teratoma cells have been found to express markers similar to those found in malignant tumors ${ }^{14}$. We recently reported that the transplantation of cell sheets reassembled with defined mouse ESC-derived cardiovascular populations resulted in functional improvement in a rat sub-acute myocardial infarction (MI) model, and no tumors formed within the 3-month observation period after transplantation ${ }^{12}$. Transplantation of such fully differentiated cells alleviates some of the risk of teratoma formation. Other reports of the 
transplantation of differentiated cells have shown increased engraftment and functional improvement ${ }^{10,13}$. While no long-term studies assessing the real risk of teratoma formation have yet been performed, the theoretical concern remains an important obstacle. The second issue concerns immunity. ESCs have been reported to express specific human leukocyte antigen (HLA) subclasses $^{15}$; this raises worries about graft rejection and might necessitate immunosuppression, which could increase the risk of surgical wound infection after cell transplantation surgery. Finally, the origin of ESCs has raised considerable ethical concerns and led to heated debates among scientists and the wider public.

The discovery that reprogramming adult somatic cells with genes that confer ESC pluripotency generates ESC-like cells, called induced pluripotent stem cells (iPSCs), may resolve the ethical and immunogenic issues associated with the use of ESCs ${ }^{16,17}$. Mouse iPSCs can be differentiated into cardiovascular cell populations almost identical to those produced from mouse ESCs, indicating that the regenerative capacity of iPSCs is almost equal to that of $\operatorname{ESCs}^{18}$. Furthermore, a potent differentiation protocol based on high-density monolayer cultures and chemically defined factors, and modifications thereof, have been reported to produce cardiomyocytes from human iPS cells with an efficiency of $40-70 \%{ }^{10,19}$. The application of this technique would strongly promote 
cardiac regenerative therapy utilizing human iPS cells. Recently, methods for generating human iPS cell lines without genomic integration by using episomal vectors ${ }^{20}$ or human artificial chromosome vectors $^{21}$ have been reported. These may reduce tumorigenesis due to mutations, which could otherwise limit the clinical application of iPSCs. Based on the results of these basic studies, iPSCs are currently thought to be one of the most promising sources of cells for cardiac regeneration. However, further careful exploration of the feasibility of this new therapeutic modality will be required before its clinical application.

\section{Bone marrow-derived stem cells}

There are various cell subsets within the bone marrow niche that possess stem cell properties; these include hematopoietic progenitor/stem cells, mesenchymal stem cells, and endothelial progenitor cells. Each of these cell populations has both advantages and disadvantages for use in cardiac regeneration (Table 1). Although the capacities of these cells to differentiate into cardiomyocytes are rather low compared with those of ESC/iPSCs, their potential for cardiac restoration has been confirmed in many preclinical studies.

Bone marrow hematopoietic stem cells (or circulating peripheral-blood progenitor 
cells) are a well characterized and abundant source of progenitor cells. A number of remarkable studies have shown that direct transplantation or mobilization from endogenous reservoirs of bone marrow-derived cells significantly improves cardiac function. Some of these studies actually demonstrated regeneration of contracting cardiomyocytes and vascular beds ${ }^{22,23}$. However, other investigations found limited or no differentiation of bone marrow cells into cardiovascular cell types ${ }^{24}$; this suggests a beneficial effect independent of direct tissue regeneration, such as neovascularization due to paracrine effects. The observed improvements in cardiac function prompted a number of clinical trials using autologous bone marrow cells to treat patients with heart failure or MI. These studies used circulating hematopoietic progenitor cells, or bone marrow mononuclear cells (MNCs), which also contain hematopoietic stem cells. While the results of small early studies were encouraging, larger, randomized, placebo-controlled and blinded studies have shown mixed results ${ }^{25,26}$. The results of the REPAIR-AMI trial (the largest of the randomized, placebo-controlled trials) were positive in that left ventricular function improved and the combined clinical endpoint of death, MI, or revascularization within 2 years was reduced ${ }^{27}$. In contrast to the improved left ventricular function found by the REPAIR-AMI trial, a recent, randomized, double-blind, placebo-controlled study (the LateTIME trial) in which autologous bone 
marrow MNCs were transplanted into patients with MI 2-3 weeks after successful percutaneous coronary intervention showed no beneficial effect on left ventricular ejection fraction $(\mathrm{LVEF})^{28}$. These apparently conflicting results may be attributable to the cell preparation or the timing of cell administration. Further large-scale trials are clearly necessary to assess the role of infused bone marrow cells in cardiac repair in order to improve the therapeutic efficacy of this promising technique.

Mesenchymal stem cells (MSCs) are a subset of stem cells found in the stroma of the bone marrow that can differentiate into osteoblasts, chondrocytes, and adipocytes ${ }^{29}$ and also into small numbers of cardiomyocytes ${ }^{30}$. MSCs are thought to be either less immunogenic than other lines ${ }^{31}$ or inherently immunomodulatory ${ }^{32}$, alleviating the need for immunosuppression or autologous therapy. Preclinical studies of transplantation of MSCs into post-infarct animals demonstrated improved left ventricular function, reduced infarct size, and increased survival rate ${ }^{30,31,33}$. A clinical study of MSCs in patients with MI demonstrated improvement of left ventricular function ${ }^{34}$. The disadvantage of MSCs for this clinical application is their broad differentiation capacity. MSC populations remain significantly heterogeneous and are therefore less predictable after transplantation. Some studies have indicated that transplanted MSCs had differentiated into osteoblasts inside ventricular tissue ${ }^{35}$. 
Another bone marrow cell subset is the endothelial progenitor cells (EPCs). In the past, angiogenesis was thought to occur exclusively though the proliferation of mature endothelial cells at injury sites. This concept has changed with the discovery that bone marrow-derived EPCs reach injury sites and incorporate into the microvasculature (vasculogenesis) ${ }^{36}$. This finding drastically altered our understanding of vascular growth and became a new therapeutic approach. EPCs can be identified by their ability to acquire endothelial cell characteristics, i.e., the expression of cell surface makers such as cluster of differentiation molecule 133 (CD133), CD34, the vascular endothelial growth factor receptor 2 kinase (VEGFR-2; also designed as KDR), and vascular endothelial cadherin (VE-cadherin), both in vitro and in vivo. Of these, CD34 ${ }^{+}$and $\mathrm{CD}_{133^{+}}$cells are the most widely recognized and utilized ${ }^{37}$. EPCs are mobilized from the bone marrow during states of injury, such as trauma, MI, or cancer ${ }^{38-40}$. The research into their use began with attempts to enhance their mobilization or incorporate EPCs directly into the vasculature of injured sites. VEGF, granulocyte colony stimulating factor (G-CSF), and statins (3-hydroxy-3-methylglutaryl coenzyme-A reductase inhibitors) have been reported to increase the mobilization of EPCs from the bone marrow $^{41-43}$. Preclinical studies of the use of EPCs to treat experimental hind-limb ischemia demonstrated significant improvements in blood-flow recovery and limb 
salvage $^{36}$. Furthermore, injection of EPCs into infarcted myocardium improved left ventricular function ${ }^{44}$. The results of a randomized multicenter clinical trial in patients with acute ischemia (REGENT trial) showed no significant improvement in left ventricular function after treatment with EPCs. However, there was a trend in favor of EPC therapy in the patients with the most severely impaired left ventricular function and in those with longer delays between the onset of symptoms and revascularization ${ }^{45}$. EPCs have already been used in the field of interventional cardiology. Drug-eluting stents (impregnated with various chemicals that inhibit neointimal thickening) reduce the restenosis rate but increase the risk of in-stent thrombosis, a potentially fatal event. GENOUS stents are coated with anti-CD34 antibodies, which work to trap circulating EPCs and augment the process of luminal endothelialization; this may prevent restenosis ${ }^{46}$. A prospective study showed that implantation of the EPC-capture stent is safe and effective, with satisfactory immediate results and mid-term outcomes and no evidence of stent thrombosis ${ }^{47}$. However, EPCs have several disadvantages as a therapeutic material. First, this cell population is heterogeneous: EPCs circulating in the peripheral blood span the full range of differentiation from angioblasts to mature endothelial cells. Second, the stem cell pool of EPCs is quite limited, and ex vivo expansion would be the only way to attain sufficient numbers of EPCs for the treatment 
of a significant injury or ischemic event ${ }^{48}$. Finally, the circulating pool of EPCs is reduced in patients with such common comorbidities of cardiac ischemic disease as diabetes mellitus, hypertension, and hypercholesterolemia ${ }^{49}$. Although further research is required to overcome these problems and to enhance the therapeutic efficiency of EPCs in ischemic tissue, these cells remain promising as a potential therapeutic material.

\section{Skeletal myoblasts}

In adult skeletal muscle, a stem cell population called "satellite cells" exists beneath the basal membrane of muscle tissue, where they lie dormant until stimulated by muscle injury to proliferate ${ }^{50}$. Skeletal myoblasts (SMs) are derived from the satellite cells. SMs have been considered an attractive source for cardiac repair for several reasons. First, these cells are further differentiated than ESCs and therefore less prone to teratoma formation. Second, they can be harvested from the host, expanded ex vivo, and autologously re-transplanted, thus avoiding the need for immunosuppression ${ }^{51}$. Third, SMs are resistant to ischemia, an obstacle to the function of stem cells in injured myocardium, and are therefore especially appropriate for cardiac repair ${ }^{52}$. Finally, SMs have the capacity to differentiate into non-muscle cell types in vitro ${ }^{53}$. Most 
transplantation experiments in animal cardiac disease models produced improved left ventricular function and decreased remodeling ${ }^{51,52,54,55}$. However, skeletal myoblasts do not fully differentiate into cardiomyocytes in vivo after transplantation, and the myotubules generated do not operate in synchrony with the surrounding myocardium ${ }^{55}$, possibly due to a lack of connexin activity and electrical coupling with the surrounding myocardial cells. However, the improvement in left ventricular function in animal models prompted a series of clinical investigations. Early clinical studies were aimed at assessing the feasibility and safety of SM implantation ${ }^{52,56,57}$. Although these studies proved the therapy feasible and showed that SMs survive in the heart, only marginal benefit was recognized. Larger scale clinical trials were undertaken to assess the benefit of myoblast therapy. The most notable to date was the Myoblast Autologous Grafting in Ischemic Cardiomyopathy (MAGIC) trial, which randomized patients to receive injection of either SMs or culture medium. The results of this trial have been disappointing in that no significant benefit of SM transplantation has been observed ${ }^{58}$. Further clinical studies are ongoing and may show different results. Several barriers to the use of SMs still remain. The first limitation is the arrhythmogenic potential of the engrafted SMs. The MAGIC trial showed a higher number of arrhythmic events in the myoblast-treated patients ${ }^{58}$. Animal experiments have shown that the electrical coupling 
of SMs to host cardiomyocytes increases when the SMs are induced to overexpress connexin 43 , indicating that their arrhythmogenicity may be a surmountable obstacle ${ }^{59}$. The second limitation is the relatively poor engraftment of the injected cells into the host myocardium. Cellular mortality of over $90 \%$ within the first few days after injection has been reported in mice ${ }^{60}$. Some studies in humans have shown similarly high rates of cell death, with only scarce surviving cells ${ }^{52}$. Clinical research on autologous myoblast-sheet transplantation for treatment of severe heart failure is now ongoing in $\operatorname{Japan}^{61}$. As the cell sheet transplantation method is thought to improve the survival of the transplants over needle injection (mentioned below), this strategy is a promising means of resolving the survival problem, and better clinical outcomes would be expected. The third limitation of SM use is that the engrafted cells differentiate into myotubules rather than cardiomyocytes and therefore do not constitute a true regenerative therapy.

\section{Cardiac stem cells}

The modest (rather unsatisfactory) functional effects of the transplantation of bone marrow cells or SMs in human studies have stimulated further research into the natural and endogenous regenerative mechanisms of cardiac tissue. The heart has traditionally 
been considered a post-mitotic organ, and mature cardiomyocytes withdraw from the proliferative cell cycle. However, contradictory data have accumulated, as cardiomyocyte proliferation and cell cycling have been observed under pathological conditions such as hypertension or $\mathrm{MI}^{62,63}$ and even in the healthy heart ${ }^{64}$. Moreover, estimates of the death rates of adult cardiomyocytes suggested the existence of a pool of cardiac progenitor cells ${ }^{65}$. This evidence prompted a search for such resident cardiac cells. Several different cell populations with stem cell characteristics were subsequently discovered in the adult heart. The first cell population with stem cell properties is called the side population (SP); these cells have also been identified in various other organs, including bone marrow, skeletal muscle, and adipose tissue ${ }^{66}$. Isolated cardiac SP cells can differentiate into cardiomyocytes, endothelial cells, or smooth muscle cells, suggesting that they represent cardiac and vascular progenitor cells ${ }^{67}$. The second putative resident progenitor population constitutes cells expressing the stem cell factor receptor c-Kit (also designed as CD117), which are located in small clusters within the adult heart. $\mathrm{c}-\mathrm{Kit}^{+}$cells have regenerative potential after transplantation and give rise to cardiomyocytes, endothelial cells, and smooth muscle cells. c-Kit ${ }^{+}$cell transplantation after ischemic injury significantly improves cardiac function ${ }^{68}$. The third cell type in the heart with stem cell properties consists of cells expressing stem cell antigen 1 (Sca-1). 
Sca- $1^{+}$cells home to infarcted myocardium and differentiate into cardiomyocytes around the injured area ${ }^{69}$. Finally, enzymatic digestion of heart tissue obtained via endomyocardial biopsy yields round cardiac progenitor cells that form so-called cardiospheres in suspension ${ }^{70}$. Cardiosphere-derived cells (CDCs) can also differentiate into cardiomyocytes, endothelial cells, and smooth muscle cells and exhibit remarkable capacities for proliferation and differentiation ${ }^{70}$. Once isolated, this cell population can be induced to differentiate into spontaneously contracting aggregates of cardiomyocytes that can then be transplanted into injured myocardium ${ }^{71}$. The injection of CDCs has produced functional improvement in preclinical studies ${ }^{71}$. Small numbers of CDCs have been observed to integrate into the injured myocardium, but this extent of cardiac tissue regeneration is insufficient to explain the functional improvement.

Cardiac stem cells appear to exist in specialized niches that support the growth and maintenance of the stem cell pool ${ }^{72}$. Putative niches have been thought to be localized throughout the myocardium ${ }^{68}$. However, there is recent evidence that the adult heart contains a resident stem cell population that originates from the epicardium and has the potential to differentiate into cardiomyocytes after $\mathrm{MI}^{73}$. Although the different cardiac stem cell pools are small relative to the number of mature resident cardiomyocytes, they are believed to be the source of the new cells in damaged myocardium ${ }^{74}$. It is unclear 
whether the various cardiac stem cells are distinct types or represent different stages of a single cell lineage. Furthermore, the cardiac stem cell pool appears to diminish with age, possibly contributing to the poor efficiency of regeneration in elderly people ${ }^{74}$. This highlights the need to discover how to rejuvenate this senescent stem cell population, as it is largely the elderly who suffer increased mortality from cardiac ischemia.

Several phase-1 clinical trials using cardiac stem cells have been performed to date ${ }^{75}$. The CArdiosphere-Derived aUtologous stem CElls to reverse ventricUlar dySfunction (CADUCEUS) study was a proof-of-principle study of intracoronary delivery of CDCs in patients with recent MI and left ventricular dysfunction ${ }^{76}$. In CADUCEUS, patients underwent endomyocardial biopsy sampling about 4 weeks after MI to generate autologous CDCs that were subsequently injected into the coronary artery. The rates of serious adverse effects and arrhythmias did not differ between patients in the CDC group and controls receiving conventional medical therapy. MRI analysis of patients treated with CDCs showed reduced scar mass and increased viable heart mass and regional contractility. However, changes in end-diastolic volume, end-systolic volume, and LVEF 6 months after transplantation did not differ between the groups. The Stem Cell Infusion in Patients with Ischemic cardiOmyopathy (SCIPIO) trial was performed in patients with post-infarction left ventricular dysfunction before coronary artery 
bypass grafting (CABG). Intracoronary administration of autologous $\mathrm{c}-\mathrm{Kit}^{+}$cardiac stem cells about 4 months after surgery improved LVEF, and no adverse effects related to cell administration were reported ${ }^{77}$. In Japan, the results of the AutoLogous Human CArdiac-Derived Stem Cell to Treat Ischemic cArdiomyopathy (ALCADIA) trial, which tested combined therapy with autologous CDC transplantation and topical administration of basic fibroblast growth factor (bFGF), are now under evaluation ${ }^{78}$. Further investigations incorporating larger numbers of patients, longer follow-up times, and a true placebo arm will be needed to confirm the safety and efficacy of cardiac stem cell therapy.

\section{Effective cell delivery: beyond needle injection}

The results of this research have led to the conclusion that stem cells may be beneficial in the treated hearts but act primarily through paracrine mechanisms rather than through direct differentiation as initially expected. However, the low rates of grafted cell survival and engraftment diminish their potential and are serious technical limitations of stem cell therapy ${ }^{79}$. Over $70 \%$ of injected cells have been reported to die progressively during the first 48 hours after needle injection due to the hypoxic, inflammatory, and/or fibrotic environment ${ }^{80}$. Another report indicates that only 5.4 to $8.8 \%$ of microspheres 
directly injected into the beating myocardium remain shortly after the injection due to massive mechanical loss ${ }^{81}$. Therefore, new strategies such as combining the cells with bioengineering techniques have been developed and are the subjects of intense research, and early results suggest that these new strategies may improve the efficiency of stem cell therapies. Initial experiments were performed by combining the cells with injectable biomaterials such as collagen, fibrin, or gelatin. Matrigel and other factors that provide a favorable environment rich in cytokines and growth factors were also tested. In general, these early studies showed increased survival of the transplanted cells and greater improvements in the cardiac function of the treated hearts ${ }^{82}$. However, these approaches did not assure complete cell retention or adequate distribution of the grafted cells. New techniques such as the creation of microtissues, i.e., cell sheets or patches, are now being developed in order to enhance both cell survival and the homogeneous and organized distribution of the cells ${ }^{83}$.

Cellular patches are created by using biomaterials that act as delivery platforms or scaffolds for the cells, assuring their engraftment and interaction with the tissue. One class of materials used is hydrogel/extracellular matrix-based matrices, in which the cells are embedded in a soluble hydrogel matrix that condenses in response to a temperature change to form a cellularized patch that can be applied to the pericardium. 
Patches of MSCs entrapped in a collagen-I matrix have been created and implanted into infarcted rat hearts, where they increased cell engraftment and functional improvement; these results appear to have been due to potentiation of the trophic effect of the MSCs by their increased survival in the tissue in the patch format ${ }^{84}$. Three-dimensional contractile loops of mixed collagen and neonatal cardiomyocytes, a more-sophisticated approach, have been successfully created. Implantation of these loops could support the contractile function of damaged heart ${ }^{85}$.

Another promising approach is the creation of cell sheets with no scaffold support. This approach would avoid inflammatory reactions against the biomaterials constituting the scaffolds. Scaffold-free sheets have been constructed using culture dishes covalently grafted with the temperature-responsive polymer poly ( $\mathrm{N}$-isopropylacrylamide) (PIPAAm), which enables the preparation of cell sheets without enzymatic digestion ${ }^{86}$. The beneficial potential of this technique has been demonstrated by the transplantation of monolayers of adipose tissue-derived $\mathrm{MSCs}^{33}$ or triple-layer cardiac tissue sheets bioengineered with ESC-derived defined cardiac cell populations (our recent report) ${ }^{12}$ into infarcted hearts. Both methods demonstrated increased tissue neovascularization and positive attenuation of heart remodeling, resulting in improved cardiac function. The direct mechanical support of the transplanted cell sheets would be desirable for 
more effective cardiac regeneration. However, no evidence of the reinforcement of contraction by the physical integration of the cell sheet and host myocardium was reported to date. To realize that, more increased survival of cell sheets would be essential, and supplemental strategies together with current cell sheet transplantation, such as vascularization of cell sheet, might be promising ${ }^{12}$.

Transplantation of in-vitro-created 3D cardiospheres has recently been shown to improve both engraftment of cardiac progenitors and their in-vivo differentiation towards cardiac and vascular cells ${ }^{87}$. De-cellularized tissues have also been explored as scaffolds for cell transplantation. Tissues such as bovine pericardium ${ }^{88}$ and omentum ${ }^{89}$ have also been used to support cell types such as mesenchymal cells in order to enhance their paracrine effects. However, obtaining sufficient cardiac cells with no immunological risk and creating patches/organs that mimic the structure and function of the heart remain challenging.

\section{Future directions for cardiac cell therapy}

In spite of the knowledge described above, the application of stem cells have been much less studied in chronically than in acutely infarcted hearts ${ }^{90}$. Indeed, stem cell therapy for chronic MI is of capital importance due to the growing patient population. 
Although the inhibition of tissue degeneration in the acute stage of the disease through paracrine effects such as angiogenesis is a main goal of cell therapy, the implementation of this strategy in hearts with chronic MI, in which the inflammation has receded and the angiogenic processes mostly ended, could also have therapeutic effects such as avoiding progression toward heart failure, reducing fibrosis, or regenerating the myocardium as a new contractile muscle mass. To date, cell therapy for chronic MI has been effective in both small and large animal models ${ }^{33,55,89}$. However, despite some exceptions, the effect on cardiac contractility is indirect rather than through true cardiac regeneration.

One future direction is the combination of stem cell therapy and conventional surgical procedures. Concomitant $\mathrm{CABG}$ and stem cell administration has been studied in patients with chronic myocardial ischemia, but the results were too marginal to justify full-scale therapeutic implementation ${ }^{58,77}$. We have previously reported that combined rat fetal cardiomyocyte injection and plication of left ventricular aneurysm resulted in sufficient functional improvement in a rat chronic MI model ${ }^{4}$. The combination of cell therapy and various surgical procedures other than $\mathrm{CABG}$, such as left ventricular reconstruction or mitral repair for ischemic mitral insufficiency, might be a promising strategy in the future and could provide hope for many patients, especially those with 
severe chronic heart failure who are ineligible for heart transplantation.

Another direction of future research is the further elucidation of the mechanisms of cardiac repair through cell therapy. Previous studies of stem cell therapy relied on injections of heterogeneous cell populations, which limited the insights they could provide into the cellular and molecular behaviors and mechanisms of action of transplanted cells. An understanding of the roles of each cell population as well as the various complex intercellular interactions in the heterogeneous populations transplanted would be a breakthrough in the improvement of cardiac cell therapy. Utilizing the mouse ES cell differentiation system to obtain defined cardiovascular populations, we recently found a major cellular mechanism, that is, cardiomyocytes are essential for sufficient cardiac restoration after sub-acute MI mainly through angiogenesis ${ }^{12}$. This approach to the elucidation of the regenerative mechanisms could be especially important in the context of chronic MI.

The last direction of future research that we introduce in this section is the "bioartificial heart." Replacing the injured area with a cardiac sheet or patch might be useful when a relatively small area of the heart is affected. However, this approach would not suffice when the heart has become nonfunctional and organ transplantation is indicated. Bioartificial hearts would be the ideal option in these cases, as they would 
theoretically avoid the problems of both organ transplants, such as donor shortages and immune rejection, and those of mechanical hearts, such as thromboembolism formation. In-vitro heart "reconstruction" using decellularized cadaveric hearts has been demonstrated to be feasible. It is possible to re-vascularize and re-muscularize a heart "skeleton" of which only the extracellular matrix has been preserved to create a new heart. Cardiomyocytes and endothelial and fibroblastic cells are perfused using a bioreactor, which provides a pulsatile flow and pacing that mimics physiological conditions. Surprisingly, such newly formed hearts can contract spontaneously ${ }^{91}$. Of course, many issues, such as methods for isolating a sufficient volume of cardiovascular cell populations without the risk of immune rejection (in this regard, iPS cells would be the ideal cell source) and preventing fatal arrhythmias, remain to be resolved before these bioartificial organs are developed to the point of clinical use. In any case, the demonstration of the possibility of creating such organs represents a great step forward in the treatment of cardiac diseases.

\section{Other research related to cardiovascular regeneration}

Interspecific chimera technology 
There are many promising approaches to cardiac regeneration besides the cell therapies discussed above. The generation of human hearts from other animals by using interspecific chimera technology with blastocyst complementation is one such approach. The injection of rat wild-type iPSCs into $\mathrm{Pdx}^{-/-}$(pancreatogenesis-disabled) mouse blastocysts was recently reported to result in the generation of normally functioning rat pancreases in $\mathrm{Pdx}^{-1-}$ mice ${ }^{92}$. This result indicates that organs derived from donor iPSCs can be generated in vivo in a xenogenic environment. The development of this technology for the generation of human hearts within size-matched animals, such as pigs, is ongoing in Japan ("NAKAUCHI Stem Cell and Organ Regeneration" project ${ }^{93}$ ). However, several problems remain to be overcome. The first of these concerns xenotransplantation. As the vessels (including the aorta and other large vessels), blood cells, nervous system, and other associated tissues would be derived from animals, while the organ itself would be of human origin, the transplantation of these chimeric organs into humans would be partial xenotransplantation rather than full allo/auto-transplantation. The generation of animals with genetically human blood vessels and nervous systems would be one solution to the potential for immunological rejection of xenotransplanted organs. The second problem is that in the abovementioned experiment, the iPSC-derived cells were found not only in the pancreas but in all organs 
and tissues, including the brain and $\operatorname{gonads}^{92}$. Without proper control of the differentiation of iPSCs, the generation of human organs in livestock animals will pose ethical issues. One approach to addressing this problem is the use of lineage-committed stem or progenitor cells in place of iPSCs. The introduction of such cells into an appropriate microenvironment at the appropriate developmental time point might allow restriction of differentiation to a particular organ.

\section{Biomaterials for efficient drug delivery}

The technology for realizing the beneficial effects of cell therapy must be further advanced before it can attain its full potential. The combination of cell therapy and local administration of proteins that induce paracrine effects such as angiogenesis is one possible method of enhancing the therapeutic potential of cell therapy. Tabata et al. have developed a system for sustained release of angiogenic cytokines, such as bFGF, from a biodegradable material, gelatin hydrogel; this system enables us to control the release of cytokines over the periods required for efficient clinical outcomes ${ }^{94}$. The addition of such sustained release of bFGF enhanced the functional benefit of the transplantation of CDCs in a porcine MI model ${ }^{71}$ and is being used in the ongoing clinical trial ALCADIA mentioned above ${ }^{78}$. 
In addition to its use in cardiac regeneration, the sustained-release system is also applicable to the treatment of critical limb ischemia. We found that the sustained release of bFGF improved the resolution of foot ulcers or other clinical symptoms in patients with severe limb ischemia in an initial phase $1-2$ study $^{95}$, and an advanced clinical trial is now ongoing. Drug delivery systems using biodegradable biomaterials could thus be a promising strategy for the advancement of cardiovascular regeneration.

\section{Gene therapy}

Another avenue of regenerative medicine is gene therapy, which is emerging as a potential treatment option in patients suffering from a wide spectrum of cardiovascular diseases, including coronary artery disease, peripheral vascular disease, vein graft failure, and in-stent restenosis ${ }^{96}$. Gene therapy, which is the direct introduction of transgenes into the vasculature or myocardium, may contribute to controlling the symptoms of cardiovascular disease and may also be able to reverse the pathological processes involved. However, before these objectives can be achieved, 3 goals must be accomplished: suitable vectors must be generated, a suitable gene or group of genes must be identified, and an appropriate delivery system must be developed. The optimal characteristics of these components may vary depending on the disease being targeted. 
Gene therapy to induce calcium upregulation in patients with advanced heart failure was recently attempted. The Calcium Upregulation by Percutaneous Administration of Gene Therapy in Cardiac Disease (CUPID), a phase-2 trial, decreased the frequency of cardiovascular events in the patient group, who received intracoronary administration of adeno-associated virus type $1 /$ sarcoplasmic reticulum $\mathrm{Ca}^{2+}-\mathrm{ATPase}{ }^{97}$. MicroRNAs (miRNAs), which are small, non-coding RNAs that regulate gene expression in a sequence-dependent manner, are also being investigated as a new modality of gene therapy for ischemic heart disease or vascular diseases ${ }^{98}$.

In 2010, Ieda et al. reported that a combination of 3 developmental transcription factors (Gata4, Mef2c, and Tbx5) rapidly, efficiently, and directly reprogrammed postnatal cardiac or dermal fibroblasts into differentiated cardiomyocyte-like cells in vitro (direct reprogramming) $)^{99}$. This technology was recently applied to an in-vivo mouse MI model in which the 3 genes were delivered by a retroviral vector, resulting in the direct reprogramming of cardiac fibroblasts within the infarction site into cardiomyocyte-like cells and the attenuation of cardiac dysfunction ${ }^{100}$. Therefore, despite concerns over the ethics and safety of gene therapy (the latter related to the potential unexpected side effects of genomic integration), it is a promising segment of the broad field of cardiovascular disease research. 


\section{Conclusion}

Herein, we introduced the status quo and future directions of stem cell therapy for treatment of cardiac disease and, more briefly, other approaches to cardiac regenerative research. We emphasize that we should not discuss which of these therapeutic modalities is to be preferred but rather consider them as components of an integrated medicine that would, as the summation of the new therapies introduced in this review and others that were not discussed, constitute a step towards the realization of cardiac regenerative therapy as a realistic option. In this context, the power of cardiovascular surgery as the integrator of basic research and clinical practice is virtually immeasurable.

Although much more work remains to be done, cardiac regenerative medicine, in conjunction with current treatment modalities, may help to further reduce the mortality and improve the quality of life of cardiovascular disease patients.

\section{Acknowledgments}


1

2

3

4

5

6

7

8

9
10

11

12

13

14

15

16

17

18

19

20

21

22

23

24

25

26

27

28

29

30

31

32

33

34

35

36

37

38

39

40

41

42

43

44

45

46

47

48

49

50

51

52

53

54

55

56

57

58

59

60

61

62

63

64

65

Disclosure of potential conflicts of interest: none to disclose. 


\section{References}

1 Sakata R, Fujii Y, Kuwano H. Thoracic and cardiovascular surgery in Japan during 2009: annual report by the Japanese Association for Thoracic Surgery. Gen Thorac Cardiovasc Surg 2011;59;636-67.

2 Joggerst SJ, Hatzopoulos AK. Stem cell therapy for cardiac repair: benefits and barriers. Expert Rev Mol Med 2009;11:e20.

3 Ohno N, Fedak PW, Weisel RD, Komeda M, Mickle DA, Li RK. Cell transplantation in non-ischemic dilated cardiomyopathy. A novel biological approach for ventricular restoration. Jpn J Thorac Cardiovasc Surg 2002;50:457-60.

4 Sakakibara Y, Tambara K, Lu F, Nishina T, Nagaya N, Nishimura K, et al. Combined procedure of surgical repair and cell transplantation for left ventricular aneurysm: an experimental study. Circulation 2002;106:I193-7.

5 Chien KR. Regenerative medicine and human models of human disease. Nature $2008 ; 453: 302-5$.

6 Thomson JA, Itskovitz-Eldor J, Shapiro SS, Waknitz MA, Swiergiel JJ, Marshall VS, et al. Embryonic stem cell lines derived from human blastocysts. Science 1998;282:1145-7. 
7 Murry CE, Keller G. Differentiation of embryonic stem cells to clinically relevant populations: lessons from embryonic development. Cell 2008;132:661-80

8 Yamashita J, Itoh H, Hirashima M, Ogawa M, Nishikawa S, Yurugi T, et al. Flk1-positive cells derived from embryonic stem cells serve as vascular progenitors. Nature 2000;408:92-6.

9 Yamashita JK, Takano M, Hiraoka-Kanie M, Shimazu C, Yan P, Yanagi K, et al. Prospective identification of cardiac progenitors by a novel single cell-based cardiomyocyte induction. FASEB J 2005;19:1534-6.

10 Laflamme MA, Chen KY, Naumova AV, Muskheli V, Fugate JA, Dupras SK, et al. Cardiomyocytes derived from human embryonic stem cells in pro-survival factors enhance function of infarcted rat hearts. Nat Biotechnol 2007;25:1015-24.

11 Sone M, Itoh H, Yamahara K, Yamashita JK, Yurugi-Kobayashi T, Nonoguchi A, et al. Pathway for differentiation of human embryonic stem cells to vascular cell components and their potential for vascular regeneration. Arterioscler Thromb Vasc Biol 2007;27:2127-34.

12 Masumoto H, Matsuo T, Yamamizu K, Uosaki H, Narazaki G, Katayama S, et al. Pluripotent stem cell-engineered cell sheets re-assembled with defined cardiovascular populations ameliorate reduction in infarct heart function through 
cardiomyocyte-mediated neovascularization. Stem Cells 2012;30:1196-205.

13 van Laake LW, Passier R, Monshouwer-Kloots J, Verkleij AJ, Lips DJ, Freund C, et al. Human embryonic stem cell-derived cardiomyocytes survive and mature in the mouse heart and transiently improve function after myocardial infarction. Stem Cell Res 2007;1:9-24.

14 Blum B, Benvenisty N. The tumorigenicity of human embryonic stem cells. Adv Cancer Res 2008;100:133-58.

15 Draper JS, Pigott C, Thomson JA, Andrews PW. Surface antigens of human embryonic stem cells: changes upon differentiation in culture. $\mathrm{J}$ Anat 2002;200:249-58.

16 Takahashi K, Yamanaka S. Induction of pluripotent stem cells from mouse embryonic and adult fibroblast cultures by defined factors. Cell 2006;126:663-76.

17 Takahashi K, Tanabe K, Ohnuki M, Narita M, Ichisaka T, Tomoda K, et al. Induction of pluripotent stem cells from adult human fibroblasts by defined factors. Cell 2007;131:861-72.

18 Narazaki G, Uosaki H, Teranishi M, Okita K, Kim B, Matsuoka S, et al. Directed and systematic differentiation of cardiovascular cells from mouse induced pluripotent stem cells. Circulation 2008;118:498-506. 
19 Uosaki H, Fukushima H, Takeuchi A, Matsuoka S, Nakatsuji N, Yamanaka S, et al. Efficient and scalable purification of cardiomyocytes from human embryonic and induced pluripotent stem cells by VCAM1 surface expression. PLoS One 2011;6:e23657.

20 Okita K, Matsumura Y, Sato Y, Okada A, Morizane A, Okamoto S, et al. A more efficient method to generate integration-free human iPS cells. Nat Methods 2011;8:409-12.

21 Hiratsuka M, Uno N, Ueda K, Kurosaki H, Imaoka N, Kazuki K, et al. Integration-free iPS cells engineered using human artificial chromosome vectors. PLoS One 2011;6:e25961.

22 Orlic D, Kajstura J, Chimenti S, Jakoniuk I, Anderson SM, Li B, et al. Bone marrow cells regenerate infarcted myocardium. Nature 2001;410:701-5.

23 Orlic D, Kajstura J, Chimenti S, Limana F, Jakoniuk I, Quaini F, et al. Mobilized bone marrow cells repair the infarcted heart, improving function and survival. Proc Natl Acad Sci U S A 2001;98:10344-9.

24 Murry CE, Soonpaa MH, Reinecke H, Nakajima H, Nakajima HO, Rubart M, et al. Haematopoietic stem cells do not transdifferentiate into cardiac myocytes in myocardial infarcts. Nature 2004;428:664-8. 
25 Leistner DM, Fischer-Rasokat U, Honold J, Seeger FH, Schächinger V, Lehmann R, et al. Transplantation of progenitor cells and regeneration enhancement in acute myocardial infarction (TOPCARE-AMI): final 5-year results suggest long-term safety and efficacy. Clin Res Cardiol 2011;100:925-34.

26 Meyer GP, Wollert KC, Lotz J, Steffens J, Lippolt P, Fichtner S, et al. Intracoronary bone marrow cell transfer after myocardial infarction: eighteen months' follow-up data from the randomized, controlled BOOST (BOne marrOw transfer to enhance ST-elevation infarct regeneration) trial. Circulation 2006;113:1287-94.

27 Assmus B, Rolf A, Erbs S, Elsässer A, Haberbosch W, Hambrecht R, et al. Clinical outcome 2 years after intracoronary administration of bone marrow-derived progenitor cells in acute myocardial infarction. Circ Heart Fail 2010;3:89-96.

28 Traverse JH, Henry TD, Ellis SG, Pepine CJ, Willerson JT, Zhao DX, et al. Effect of intracoronary delivery of autologous bone marrow mononuclear cells 2 to 3 weeks following acute myocardial infarction on left ventricular function: the LateTIME randomized trial. JAMA 2011;306:2110-9.

29 Jiang Y, Jahagirdar BN, Reinhardt RL, Schwartz RE, Keene CD, Ortiz-Gonzalez $\mathrm{XR}$, et al. Pluripotency of mesenchymal stem cells derived from adult marrow. 
Nature 2002;418:41-9.

30 Tomita S, Li RK, Weisel RD, Mickle DA, Kim EJ, Sakai T, et al. Autologous transplantation of bone marrow cells improves damaged heart function. Circulation 1999;100:II247-II256.

31 Dai W, Hale SL, Martin BJ, Kuang JQ, Dow JS, Wold LE, et al. Allogeneic mesenchymal stem cell transplantation in postinfarcted rat myocardium: short- and long-term effects. Circulation 2005;112:214-23.

32 Le Blanc K, Ringdén O. Immunomodulation by mesenchymal stem cells and clinical experience. J Intern Med 2007;262:509-25.

33 Miyahara Y, Nagaya N, Kataoka M, Yanagawa B, Tanaka K, Hao H, et al. Monolayered mesenchymal stem cells repair scarred myocardium after myocardial infarction. Nat Med 2006;12:459-65.

34 Chen SL, Fang WW, Ye F, Liu YH, Qian J, Shan SJ, et al. Effect on left ventricular function of intracoronary transplantation of autologous bone marrow mesenchymal stem cell in patients with acute myocardial infarction. Am J Cardiol 2004;94:92-5.

35 Yoon YS, Park JS, Tkebuchava T, Luedeman C, Losordo DW. Unexpected severe calcification after transplantation of bone marrow cells in acute myocardial infarction. Circulation 2004;109:3154-7. 
36 Asahara T, Murohara T, Sullivan A, Silver M, van der Zee R, Li T, et al. Isolation of putative progenitor endothelial cells for angiogenesis. Science 1997;275:964-7.

37 Hristov M, Weber C. Endothelial progenitor cells in vascular repair and remodeling. Pharmacol Res 2008;58:148-51.

38 Gill M, Dias S, Hattori K, Rivera ML, Hicklin D, Witte L, et al. Vascular trauma induces rapid but transient mobilization of VEGFR2(+)AC133(+) endothelial precursor cells. Circ Res 2001;88:167-74.

39 Shintani S, Murohara T, Ikeda H, Ueno T, Honma T, Katoh A, et al. Mobilization of endothelial progenitor cells in patients with acute myocardial infarction. Circulation 2001;103:2776-9.

40 Patenaude A, Parker J, Karsan A. Involvement of endothelial progenitor cells in tumor vascularization. Microvasc Res 2010;79:217-23.

41 Kalka C, Tehrani H, Laudenberg B, Vale PR, Isner JM, Asahara T, et al. VEGF gene transfer mobilizes endothelial progenitor cells in patients with inoperable coronary disease. Ann Thorac Surg 2000;70:829-34.

42 Fukuhara S, Tomita S, Nakatani T, Ohtsu Y, Ishida M, Yutani C, et al. G-CSF promotes bone marrow cells to migrate into infarcted mice heart, and differentiate into cardiomyocytes. Cell Transplant 2004;13:741-8. 
43 Llevadot J, Murasawa S, Kureishi Y, Uchida S, Masuda H, Kawamoto A, et al. HMG-CoA reductase inhibitor mobilizes bone marrow-derived endothelial progenitor cells. J Clin Invest 2001;108:399-405.

44 Kocher AA, Schuster MD, Szabolcs MJ, Takuma S, Burkhoff D, Wang J, et al. Neovascularization of ischemic myocardium by human bone-marrow-derived angioblasts prevents cardiomyocyte apoptosis, reduces remodeling and improves cardiac function. Nat Med 2001;7:430-6.

45 Tendera M, Wojakowski W, Ruzyłło W, Chojnowska L, Kepka C, Tracz W, et al. Intracoronary infusion of bone marrow-derived selected CD34+CXCR4+ cells and non-selected mononuclear cells in patients with acute STEMI and reduced left ventricular ejection fraction: results of randomized, multicentre Myocardial Regeneration by Intracoronary Infusion of Selected Population of Stem Cells in Acute Myocardial Infarction (REGENT) Trial. Eur Heart J 2009;30:1313-21.

46 den Dekker WK, Houtgraaf JH, Onuma Y, Benit E, de Winter RJ, Wijns W, et al. Final results of the HEALING IIB trial to evaluate a bio-engineered CD34 antibody coated stent (Genous ${ }^{\mathrm{TM}}$ Stent) designed to promote vascular healing by capture of circulating endothelial progenitor cells in CAD patients. Atherosclerosis 2011;219:245-52. 
47 Miglionico M, Patti G, D'Ambrosio A, Di Sciascio G. Percutaneous coronary intervention utilizing a new endothelial progenitor cells antibody-coated stent: a prospective single-center registry in high-risk patients. Catheter Cardiovasc Interv 2008;71:600-4.

48 Jujo K, Ii M, Losordo DW. Endothelial progenitor cells in neovascularization of infarcted myocardium. J Mol Cell Cardiol 2008;45:530-44.

49 Vasa M, Fichtlscherer S, Aicher A, Adler K, Urbich C, Martin H, et al. Number and migratory activity of circulating endothelial progenitor cells inversely correlate with risk factors for coronary artery disease. Circ Res 2001;89:E1-7.

50 Buckingham M, Montarras D. Skeletal muscle stem cells. Curr Opin Genet Dev 2008;18:330-6.

51 Murry CE, Wiseman RW, Schwartz SM, Hauschka SD. Skeletal myoblast transplantation for repair of myocardial necrosis. J Clin Invest 1996;98:2512-23.

52 Pagani FD, DerSimonian H, Zawadzka A, Wetzel K, Edge AS, Jacoby DB, et al. Autologous skeletal myoblasts transplanted to ischemia-damaged myocardium in humans. Histological analysis of cell survival and differentiation. J Am Coll Cardiol 2003;41:879-88.

53 Arsic N, Mamaeva D, Lamb NJ, Fernandez A. Muscle-derived stem cells isolated 
as non-adherent population give rise to cardiac, skeletal muscle and neural lineages.

Exp Cell Res 2008;314:1266-80.

54 Taylor DA, Atkins BZ, Hungspreugs P, Jones TR, Reedy MC, Hutcheson KA, et al. Regenerating functional myocardium: improved performance after skeletal myoblast transplantation. Nat Med 1998;4:929-33.

55 Farahmand P, Lai TY, Weisel RD, Fazel S, Yau T, Menasché P, et al. Skeletal myoblasts preserve remote matrix architecture and global function when implanted early or late after coronary ligation into infarcted or remote myocardium. Circulation 2008;118:S130-7.

56 Siminiak T, Fiszer D, Jerzykowska O, Grygielska B, Rozwadowska N, Kałmucki P, et al. Percutaneous trans-coronary-venous transplantation of autologous skeletal myoblasts in the treatment of post-infarction myocardial contractility impairment: the POZNAN trial. Eur Heart J 2005;26:1188-95.

57 Dib N, Dinsmore J, Lababidi Z, White B, Moravec S, Campbell A, et al. One-year follow-up of feasibility and safety of the first U.S., randomized, controlled study using 3-dimensional guided catheter-based delivery of autologous skeletal myoblasts for ischemic cardiomyopathy (CAuSMIC study). JACC Cardiovasc Interv 2009;2:9-16. 
58 Menasché P, Alfieri O, Janssens S, McKenna W, Reichenspurner H, Trinquart L, et al. The Myoblast Autologous Grafting in Ischemic Cardiomyopathy (MAGIC) trial: first randomized placebo-controlled study of myoblast transplantation. Circulation 2008;117:1189-200.

59 Roell W, Lewalter T, Sasse P, Tallini YN, Choi BR, Breitbach M, et al. Engraftment of connexin 43-expressing cells prevents post-infarct arrhythmia. Nature 2007;450:819-24.

60 Suzuki K, Murtuza B, Beauchamp JR, Smolenski RT, Varela-Carver A, Fukushima $\mathrm{S}$, et al. Dynamics and mediators of acute graft attrition after myoblast transplantation to the heart. FASEB J 2004;18:1153-5.

61 Development of new strategy for severe heart failure using autologous myoblast sheets. UMIN Clinical Trials Registry (UMIN-CTR). http://www.umin.ac.jp/ctr/index-j.htm UMIN000003273 (accessed Apr 8, 2012).

62 Anversa P, Palackal T, Sonnenblick EH, Olivetti G, Capasso JM. Hypertensive cardiomyopathy. Myocyte nuclei hyperplasia in the mammalian rat heart. J Clin Invest 1990;85:994-7.

63 Beltrami AP, Urbanek K, Kajstura J, Yan SM, Finato N, Bussani R, et al. Evidence that human cardiac myocytes divide after myocardial infarction. N Engl J Med 
2001;344:1750-7.

64 Bergmann O, Bhardwaj RD, Bernard S, Zdunek S, Barnabé-Heider F, Walsh S, et al. Evidence for cardiomyocyte renewal in humans. Science 2009;324:98-102.

65 Ellison GM, Torella D, Karakikes I, Nadal-Ginard B. Myocyte death and renewal: modern concepts of cardiac cellular homeostasis. Nat Clin Pract Cardiovasc Med 2007;4:S52-9.

66 Challen GA, Little MH. A side order of stem cells: the SP phenotype. Stem Cells 2006;24:3-12.

67 Oyama T, Nagai T, Wada H, Naito AT, Matsuura K, Iwanaga K, et al. Cardiac side population cells have a potential to migrate and differentiate into cardiomyocytes in vitro and in vivo. J Cell Biol 2007;176:329-41.

68 Beltrami AP, Barlucchi L, Torella D, Baker M, Limana F, Chimenti S, et al. Adult cardiac stem cells are multipotent and support myocardial regeneration. Cell 2003;114:763-76.

69 Oh H, Bradfute SB, Gallardo TD, Nakamura T, Gaussin V, Mishina Y, et al. Cardiac progenitor cells from adult myocardium: homing, differentiation, and fusion after infarction. Proc Natl Acad Sci U S A 2003;100:12313-8.

70 Messina E, De Angelis L, Frati G, Morrone S, Chimenti S, Fiordaliso F, et al. 
Isolation and expansion of adult cardiac stem cells from human and murine heart.

Circ Res 2004;95:911-21.

71 Takehara N, Tsutsumi Y, Tateishi K, Ogata T, Tanaka H, Ueyama T, et al. Controlled delivery of basic fibroblast growth factor promotes human cardiosphere-derived cell engraftment to enhance cardiac repair for chronic myocardial infarction. J Am Coll Cardiol 2008;52:1858-65.

72 Moore KA, Lemischka IR. Stem cells and their niches. Science 2006;311:1880-5.

73 Smart N, Bollini S, Dubé KN, Vieira JM, Zhou B, Davidson S, et al. De novo cardiomyocytes from within the activated adult heart after injury. Nature 2011;474:640-644.

74 Torella D, Ellison GM, Méndez-Ferrer S, Ibanez B, Nadal-Ginard B. Resident human cardiac stem cells: role in cardiac cellular homeostasis and potential for myocardial regeneration. Nat Clin Pract Cardiovasc Med 2006;3:S8-13.

75 Siu CW, Tse HF. Cardiac regeneration: messages from CADUCEUS. Lancet 2012;379:870-1.

76 Makkar RR, Smith RR, Cheng K, Malliaras K, Thomson LE, Berman D, et al. Intracoronary cardiosphere-derived cells for heart regeneration after myocardial infarction (CADUCEUS): a prospective, randomised phase 1 trial. Lancet 
2012;379:895-904.

77 Bolli R, Chugh AR, D'Amario D, Loughran JH, Stoddard MF, Ikram S, et al. Cardiac stem cells in patients with ischaemic cardiomyopathy (SCIPIO): initial results of a randomised phase 1 trial. Lancet 2011;378:1847-57.

78 AutoLogous human CArdiac-Derived stem cell to treat Ischemic cArdiomyopathy (ALCADIA) trial. http://clinicaltrials.gov/ct2/show/ NCT00981006 (accessed Apr 8, 2012).

79 Pelacho B, Mazo M, Gavira JJ, Prósper F. Adult stem cells: from new cell sources to changes in methodology. J Cardiovasc Transl Res 2011;4:154-60.

80 Müller-Ehmsen J, Whittaker P, Kloner RA, Dow JS, Sakoda T, Long TI, et al. Survival and development of neonatal rat cardiomyocytes transplanted into adult myocardium. J Mol Cell Cardiol 2002;34:107-16.

81 Teng CJ, Luo J, Chiu RC, Shum-Tim D. Massive mechanical loss of microspheres with direct intramyocardial injection in the beating heart: implications for cellular cardiomyoplasty. J Thorac Cardiovasc Surg 2006;132:628-32.

82 Cortes-Morichetti M, Frati G, Schussler O, Duong Van Huyen JP, Lauret E, Genovese JA. Association between a cell-seeded collagen matrix and cellular cardiomyoplasty for myocardial support and regeneration. Tissue Eng 
2007;13:2681-7.

83 Christman KL, Lee RJ. Biomaterials for the treatment of myocardial infarction. J Am Coll Cardiol 2006;48:907-13.

84 Simpson D, Liu H, Fan TH, Nerem R, Dudley SC Jr. A tissue engineering approach to progenitor cell delivery results in significant cell engraftment and improved myocardial remodeling. Stem Cells 2007;25:2350-7.

85 Zimmermann WH, Melnychenko I, Wasmeier G, Didié M, Naito H, Nixdorff U, et al. Engineered heart tissue grafts improve systolic and diastolic function in infarcted rat hearts. Nat Med 2006;12:452-8.

86 Okano T, Yamada N, Sakai H, Sakurai Y. A novel recovery system for cultured cells using plasma-treated polystyrene dishes grafted with poly (N-isopropylacrylamide). J Biomed Mater Res 1993;27:1243-51.

87 Bartosh TJ, Wang Z, Rosales AA, Dimitrijevich SD, Roque RS. 3D-model of adult cardiac stem cells promotes cardiac differentiation and resistance to oxidative stress. J Cell Biochem 2008;105:612-23.

88 Wei HJ, Chen CH, Lee WY, Chiu I, Hwang SM, Lin WW, et al. Bioengineered cardiac patch constructed from multilayered mesenchymal stem cells for myocardial repair. Biomaterials. 2008;29:3547-56. 
89 Shudo Y, Miyagawa S, Fukushima S, Saito A, Shimizu T, Okano T, et al. Novel regenerative therapy using cell-sheet covered with omentum flap delivers a huge number of cells in a porcine myocardial infarction model. $\mathrm{J}$ Thorac Cardiovasc Surg 2011;142:1188-96.

90 Mazo M, Pelacho B, Prósper F. Stem cell therapy for chronic myocardial infarction. J Cardiovasc Transl Res 2010;3:79-88.

91 Ott HC, Matthiesen TS, Goh SK, Black LD, Kren SM, Netoff TI, et al. Perfusion-decellularized matrix: using nature's platform to engineer a bioartificial heart. Nat Med 2008;14:213-21.

92 Kobayashi T, Yamaguchi T, Hamanaka S, Kato-Itoh M, Yamazaki Y, Ibata M, et al. Generation of rat pancreas in mouse by interspecific blastocyst injection of pluripotent stem cells. Cell 2010;142:787-99.

93 Exploratory Research for Advanced Technology (ERATO), Japan Science and Technology Agency (JST). http://www.jst.go.jp/erato/project/nks_P/nks_P.html

94 Tabata Y. Tissue regeneration based on growth factor release. Tissue Eng 2003;9:S5-15.

95 Marui A, Tabata Y, Kojima S, Yamamoto M, Tambara K, Nishina T, et al. A novel approach to therapeutic angiogenesis for patients with critical limb ischemia by 
sustained release of basic fibroblast growth factor using biodegradable gelatin hydrogel: an initial report of the phase I-IIa study. Circ J 2007;71:1181-6.

96 Gaffney MM, Hynes SO, Barry F, O'Brien T. Cardiovascular gene therapy: current status and therapeutic potential. Br J Pharmacol 2007;152:175-88.

97 Jessup M, Greenberg B, Mancini D, Cappola T, Pauly DF, Jaski B, et al. Calcium Upregulation by Percutaneous Administration of Gene Therapy in Cardiac Disease (CUPID): a phase 2 trial of intracoronary gene therapy of sarcoplasmic reticulum Ca2+-ATPase in patients with advanced heart failure. Circulation 2011;124:304-13.

98 Frost RJ, van Rooij E. miRNAs as therapeutic targets in ischemic heart disease. J Cardiovasc Transl Res 2010;3:280-9.

99 Ieda M, Fu JD, Delgado-Olguin P, Vedantham V, Hayashi Y, Bruneau BG, et al. Direct reprogramming of fibroblasts into functional cardiomyocytes by defined factors. Cell 2010;142:375-86.

100 Qian L, Huang Y, Spencer CI, Foley A, Vedantham V, Liu L, et al. In vivo reprogramming of murine cardiac fibroblasts into induced cardiomyocytes. Nature 2012;485:593-8. 
1

2 3 4 5 6 7 8 10 11 12 13 14 15 16 17 18 19 20 21 22 23 24 25 26 27 28 29 30 31 32 33 34 35 36 37 38 39 40 41 42 43 44 45 46 47 48 49 50 51 52 53 54 55 56 57 58 59 60 61 62 63 64 65

\section{Table Legends}

Table 1:

Characteristics of stem-cell populations used for cardiac cell transplantation therapy. 


\section{Stem cell type}

Pluripotent stem cells

Embryonic stem cells (ESCs)

Dluripotent stem cells

Bone-marrow derived stem cells

Hematopoietic stem cells

(circulating progenitor cells, bone

marrow mononuclear cells)

Mesenchymal stem cells

Endothelial progenitor cells

Skeletal myoblasts

Special niches in the

myocardium

\section{Origin}

Inner cell mass of the

preimplantation blastocyst

Most somatic cells (e.g.,

skin fibroblasts)

Bone marrow, peripheral

blood

Bone marrow (adherent

cells), adipose tissue

Bone marrow, peripheral

blood

Mature skeletal muscle

\section{Advantages}

Theoretically unlimited self-renewal

capacity; pluripotency

Same advantages as ESCs; free from

ethical/immunological issues

Easy to isolate; safe and feasible to

transplant

Easy to isolate and expand in culture;

less immunogenic than other lines;

\section{multipotent}

Mobilized from bone marrow or

present in peripheral blood; important

in vasculogenesis

Extensive scalability; resistance to

ischemia; multipotent; no teratoma

formation

Resident in therecipient heart; robust

cardiovascular differentiation potential;

reduced tumor formation

\section{Disadvantages}

Ethical considerations; teratoma

formation; graft-versus-host disease

Potential teratoma formation

None

Limited potential for differentiation

into cardiomyocytes and vascular

cells

Great heterogeneity; heterotopic

differentiation (e.g., ossification)

Heterogeneity; small populations;

reduced in individuals with

cardiovascular comorbidities

Potential for arrhythmias; lack of

cardiomyocyte differentiation

Stem cell pool appears to undergo

senescence; scalability largely

unknown

\section{Clinical trials}

TOPCARE-AMI ${ }^{25}$, BOOST $^{26}$, REPAIR-AMI ${ }^{27}$, LateTIME ${ }^{28}$

Report from Chen et al.

$(\text { China })^{34}$

REGENT $^{45}$

$\mathrm{MAGIC}^{58}, \mathrm{CAuSMIC}^{57}$

CADUCEUS $^{76}$, SCIPIO $^{77}$,

ALCADIA $^{78}$

Table 1: Characteristics of stem cell populations used for cardiac cell transplantation therapy. 